\title{
INTEGRATIONIST TRIADIC AGENDAS FOR CITY RESEARCH: CASES FROM RECENT URBAN STUDIES
}

\author{
Ashraf M. SALAMA \\ Department of Architecture, University of Strathclyde, Glasgow, United Kingdom
}

Received 19 September 2019; accepted 17 October 2019

\begin{abstract}
With more than $60 \%$ of the world population living in urban areas, cities are becoming at the centre of attention in academic institutions and government organizations. However, there appears to be a continuous fragmentation in the types of knowledge developed where issues or concerns are always addressed in isolation and many factors critical to a comprehensive understanding of cities towards creating better urban environments are oversimplified at best or ignored at worst. Therefore, the thrust of this paper is to demonstrate the thought processes involved in instigating frameworks, raising questions, and establishing objectives for responsive city research. It aims to present two triadic agendas that untangle the essential components of city research; the first is the Lefebvrian triadic conception on the production of space and the second is the triadic perspective of lifestyles theories for understanding housing developments, typologies, and choices. Contextually, while the theoretical underpinnings of these agendas are developed based on a body of knowledge generated in the context of the Western world, their conceptualisation is adapted to grasp and examine key unique particularities of selected emerging (and globalised) Arab cities in the Gulf region. Calling for the need for a trans-disciplinary thinking paradigm for city research, the two agendas adopt an integrationist approach that is amenable to understanding the urban realities of these cities.
\end{abstract}

Keywords: urban research, transdisciplinarity, emerging cities, production of space, lifestyle theories.

\section{Introduction: Contextualisation - underpinning interpretations on city research}

Deciphering the complexity of city research or the development of comprehensive knowledge on cities and within the current rapid transformations of urban, social, and economic environments warrants the initiation of a brief overview on the conception of cities which has evolved since the early $20^{\text {th }}$ century. This would act as the theoretical base for the two integrationist agendas for city research identified for this paper and the subsequent operationalization of these agendas into research frameworks and implementation programmes.

The Chicago School has been the creator of modern sociology since the 1920s (Bulmer, 1984; Turner, 1988; Hutchison, 2010). Its key figures in modern urban research included social scientists such as Robert Ezra Park and Ernest Watson Burgess. Their book Introduction to the Science of Sociology (1921) proposed that cities should be viewed as urban laboratories and are actually governed by forces similar to those within ecosystems. The greatest force they acknowledged was competition, seen as the result of different groups within the city fighting for urban resources. In the succeeding decades, sociology placed emphasis on developing new analytical tools within urban ecology to examine social structures and their relation to existing and potential spatial developments. Nevertheless, since the 1960s and with the first urban crises post World War II; there has been a renewed methodical discourse within urban research that led subsequently to redefining the conceptual understanding of cities (Hall, 2002). The growing criticism of capitalism and the ills it has produced has led to a more metaphysical approach to the understanding of the urban phenomenon. One of the prominent scholars in this regard was Manuel Castells who introduced the collective consumption theory (Castells, 1972) through which cities are regarded as the product of public interventions defining urban morphologies by policies and infrastructures such as public housing and public transport. The result of this shift in focus was what is often referred to as the "new urban sociology" where attention to governance and decision-making started to reflect significantly on city research.

*Corresponding author. E-mail: ashraf.salama@strath.ac.uk 
The work of David Harvey represents an important developmental shift in city research that took place during the 1960s and 1970s. Only four years after he introduced one of the benchmarks of quantitative sociological research with his book Explanations in Geography (1969), his book Social Justice and the City has consequently become one of the classical influential writings within an emerging movement known as "radical geography." Harvey placed emphasis on analysing the political economy of space (Harvey, 1969, 1973). Some years later, in his 1982 book Limits to Capital he argued that the various circles of economic reproduction are what actually define urban structures and thus urban and spatial environments. Notably, during 1980s the discourse generated by Castells and Harvey was heavily criticised because of its abstract and intangible nature with respect to the conceptions of cities. Despite their effort to analyse the production of urban environments from a universal perspective, their theories were increasingly perceived as limiting to innovative empirical urban research and were later marginalised due to the emerging focus on decentralised urban governance and the emergence of regional and global hubs within expanding networks. This has shifted the attention from theoretical models within historical contexts to a new prominence given to contemporary concerns that speak to global condition and the resulting urban realities (Brenner \& Keil, 2006).

The global condition was coupled with the transformation from welfare-state interest in mass production to more flexible forms of urbanism within globalisation. This has developed into new conceptions of cities as knots or nodes within networks. Castells supported this new shift within urban research when he introduced the "space of flows" (Castells, 1989). In his view, space is in fact the material support of time-sharing social practices and thus the space of flows is the actual material organisation of time-sharing social practices that work through flows of people, goods and information. This was also supported through the work of key scholars from other disciplines such as Arjun Appadurai, anthropologist and a key figure in global studies, who argued for the notion of flows (Appadurai, 1996, 2001). Consequently, urban research shifted to a focus on large-scale regional and global contexts away from local or small-scale morphologies.

The preceding understanding was earlier instigated through various theories introduced in 1980s and 1990s. David Cohen contended that changes in the structure of advanced corporate services had led to the emergence of "global cities" that would serve as international centres for transnational practices and business decision-making and thus would have an increasing impact on urban morphologies worldwide (Cohen, 1981). Later theories from scholars in planning and geography such as Friedman and Goetz Wolff - their theory of a hierarchical order of World Cities (Friedman \& Wolff, 1982) and Saskia Sassen - her global city theory focusing on global control capabilities were widely accepted and eventually influential over the past two decades (Sassen, 1991; Taylor, 2003). While these new theories have had a major impact on the contempo- rary understanding of cities, what they share in common is a focus on the key aspects that drive developments in the context of the particular time they were produced. It is noted however that since the beginning of modern globalisation cities have entered a fierce competition to attract investment in order to transform into key hubs within expanding networks. Cities were described as "growth machines" (Molotch, 1976) and instead of various groups competing within the city to gain more urban resources; cities themselves are now competing to sustain their economies and influence (Salama \& Wiedmann, 2013).

From a comparative perspective while cities in highly industrialised countries benefited from already existing infrastructure and their large size and thus were able to establish local markets, it was necessary for cities in emerging countries to initiate new development strategies in order to attract urban growth since the end of the $20^{\text {th }}$ century in order to compete. This growth resulted in rapid urbanisation processes and the mass migration of new inhabitants. There is no doubt that this postulation applies clearly to cities in South-East Asia and the Middle East. Taking the production of housing as an example, housing markets, were to react to rapidly increasing demand in various areas, from studio apartments for short-term stays to family dwellings and gentrification trends. While the demand-driven aspects can be observed as rather limited during the early years of urban growth in these cities, a diversification process of housing typologies could be witnessed during the following period due to a more globalised and sophisticated real estate industry (Bardhan \& Kroll, 2007).

At local levels, numerous factors determine the housing types preferred by migrant groups in emerging cities. This can be observed in cases of migrants from rural or urban places as well as migrants from various socioeconomic and sociocultural backgrounds (Salama, 2011, 2015). While a low-income background generally limits the choice of housing and thus determines certain lifestyles, high-income groups have a larger variety of residences to choose from (Narwold \& Sandy, 2010). This is evident in the increasing diversity of upper real estate markets, while affordable housing schemes often follow more repetitive models, largely determined by land prices and construction costs (Gurran, Milligan, Baker, \& Bugg, 2007). Nonetheless, these parameters are dependent on general infrastructural networks and development policies. Therefore, new housing development patterns can be identified in emerging cities, particularly in the Global South, where they face a continuous upgrading and updating process rooted in new dynamics, including rising land and rental prices, new demographic characteristics and the economic realities resulting from various migration patterns (Aerni, 2016).

\section{Conceptualisation: Two integrationist agendas}

Following the foregoing overview of key theoretical underpinnings two schematic frameworks can be established to unravel the essential components of city research. Two key issues are identified relevant to a comprehensive 
understanding of urban development processes and an inclusive conception of lifestyle theories as they apply to housing developments and choices. These integrationist agendas were initially developed as frameworks explored and tested in the context of emerging multicultural cities in the Gulf region.

\subsection{Agenda 1: The Lefebvrian triadic conception and the production of space}

Henri Lefebvre's argument on cities and space production was seen as ground-breaking: he posits that in order to better understand the dynamics of cities; their space production should be viewed more holistically and comprehensively, beyond the particular contexts and constraints of a specific time period (Merrifield, 2006; Shields, 1999). By focusing on abstract theories and models as well as new empirical methods to comprehend cities, Lefebvre claimed that space was, in actuality, a product of complex "social superstructures". In his two most influential works La Revolution Urbaine (1972) and La production de lespace (1974), he argues that space cannot be understood as a simple collection of elements because a society's space is actually a product that has been created through its own individual spatial practice (Lefebvre, 1991, 2003).

Lefebvre developed the oft-quoted triad of "conceived, perceived and lived space" (Figure 1), also known as the first ontological transformation of space. He defined "conceived space" as the space conceptualised by scientists, planners, social engineers and other experts. These representations are abstract as they are rooted in the principles, beliefs and visions held by such practitioners, decision makers and others who are in a position to impose their personal notion of "order" on the concrete world, and so

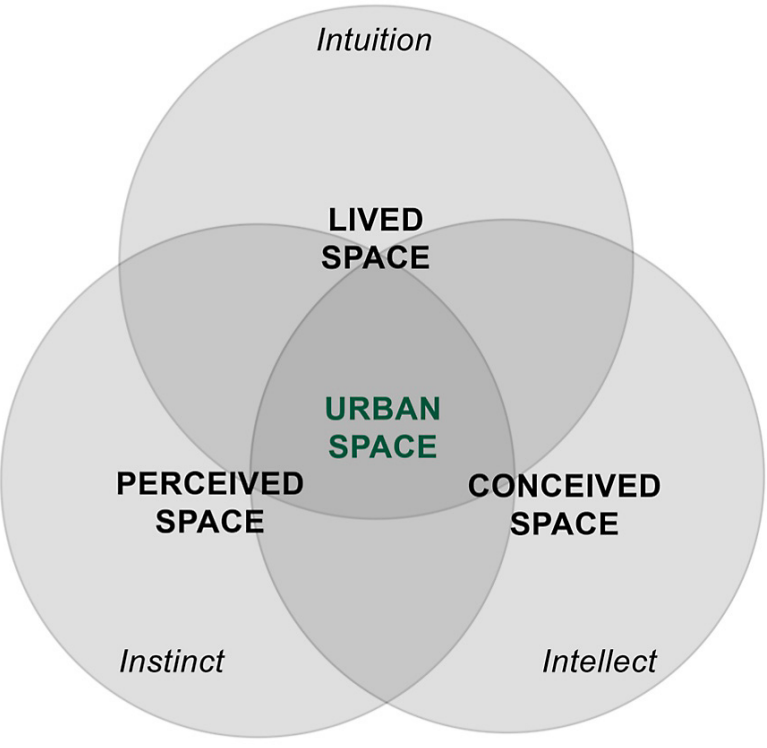

Figure 1. The Lefebvrian triadic conception of space (Salama \& Wiedmann, 2013) create a practical impact on space within social and political practice. Conceived space is thus based on knowledge and science in combination with ideology, with various experts identifying space with their own understanding of how it is planned and how it can influence and be influenced in future. Whether or not the thoughts and beliefs of these experts about space are actually valid and true is another question, but what is more pertinent is that from a subjective point of view, these conceptions of space are usually held to be true by those who apply them in their work, hence they are in actuality "representations" of space. Due to the central role of decision-making in this process, conceived space is the dominant factor producing space in contemporary societies.

The second is the "perceived space" understood as the space of "spatial practice" where movement and interaction take place, the space where networks develop and materialise. This space includes both daily routines on an individual level and urban realities such as the networks that link places designated for work, leisure and "private" life. Lefebvre maintains that the specific spatial practice of a society can only be assessed empirically by analysing and studying the structure of its networks. Because spatial practice is empirically measurable, it is also referred to as the readable or visible space that can be seen, described and analysed on many levels such as the specific sectors of architecture, city planning and urbanism, as well as the general organisation of life and the urban reality inhabited by people.

The third space, "lived space" can be comprehended as the direct unconscious, non-verbal relationship of humans to space; also known as "representational space", it is directly lived through associated images and symbols. The lived space is essentially subjective - a passive experience wherein the outer physical space echoes with the inner imagination, and makes symbolic use of outer objects, either retaining or rejecting them according to an arbitrary and subjective system of priorities and preferences. Specific locations within given vicinity can, for example, become focal points because of their position and status within the representational space of the particular community of people who use that vicinity, for instance, a religious building, a graveyard, or a square. Products of representational space are often symbolic works such as art, poetry and aesthetic trends.

Beyond the three "spaces" depicted above, the production of social space as a whole has a direct impact on the environment and, in the case of emerging multicultural cities in the Gulf region, it materialises into the built reality. The "conceived, perceived and lived space" triad can be directly utilised within the process of understanding spatial developments. The three "spaces" and the relationships that ensue between them are significantly relevant to the development of a holistic analytical framework for examining space production in cities, particularly in the context of the investigation of urban qualities. Certainly, this is not as an abstract model reduced to comparative studies of 
ideologies relevant to the three "spaces" but an integrationist agenda that enables the development of comprehensive knowledge within the current rapid transformations of urban, social, and economic environments.

\subsection{Agenda 2: The triadic perspective of lifestyles theories and understanding housing typologies, and choices}

Lifestyle research has recently played an increasingly important role in understanding housing patterns and consequently urban development dynamics. This is based on the notion that lifestyles lead to certain housing choices; therefore new housing developments can be studied as a reflection of these new lifestyles. Rightly, contemporary literature emphasises that housing is more than the pure need for shelter. The home environment can be seen as both a form of self-expression and an important spatial factor defining human perceptions (Marcus, 1997). Where and how a human was raised will always affect future choices and his or her acceptance of certain residential quality. Additionally, the age, income level and household size often impacts the preference of certain housing types. To study the relationship between housing and lifestyles, basic needs must first be identified (Freeman, 1998). While the need for shelter can be seen as the lowest level of needs based on the simple premise of human survival, the social needs to establish a sense of belonging are followed by the individual needs of self-expression (Newmark \& Thompson, 1977).

In principle, lifestyle theories are based on a complex agenda that acknowledges the reality of human beings driven by dynamic interactive factors rather than static personal and situational factors and builds on the earlier work he developed in the context of the city of Jeddah, Saudi Arabia and more recently in the context of emerging cities within Gulf States (Salama, 2006, 2011; Salama, Wiedmann, \& Ibrahim, 2017).

The French philosopher and sociologist Pierre Bourdieu introduced the concept of habitus as the result of both the hexis (a more or less stable disposition of knowledge or character) and more complex mental and subjective schemes of perception (Bourdieu, 1987; Benedikter, 2012). Habitus refers to past experiences resulting in different skills, personalities and habits, which lead to certain socio-behavioural practices. According to Bourdieu, each social class shares a certain general habitus due to similar environments, backgrounds and thus experiences. This habitus has a direct impact on each individual leading to dynamics between given constructs, which have developed over generations, and new individual perceptions introducing certain restructuring processes. The habitus can thus be identified as a holistic approach towards understanding the origin of lifestyles and the result of a longterm historic evolution, which is continuously changing. Bourdieu maintains that individuals need their habitus to find new solutions based on their intuition, which in his view is directly linked to societal norms. The resulting lifestyles have significant impact on how social structures and spatial development patterns evolve because they influence the ideas that define a good society.

The British anthropologist Mary Douglas introduced the "group and grid" model in her book "Natural Symbols" (Douglas, 1970). A group implies a general boundary around a community, which is based on choice, and a grid includes the outer forces and regulations. Douglas distinguishes between four main group-grid types: the "isolate", the "positional", the "individualist", and the "enclave". While the "isolate" only includes social groups that have been isolated by the system, such as prisoners, and therefore hardly has any impact on developments, the "individualist" is primarily concerned with private benefits and is therefore a product of an increasingly commercial society. Therefore, social status and its expression can play an important role in housing dynamics. The "positional" is rooted in a distinct group following a clear grid-given structure and thus often supports tradition and order (Douglas, 2006). Finally, the "enclave" includes all groups that refuse to participate in any given framework and follow their own structures. These four fundamental types offer an enhanced understanding of key lifestyle dynamics. The diversity of lifestyles is thus highly dependent on the general social structure.

In addition to the holistic approach of understanding lifestyles as the result of the habitus as defined by Bourdieu and following the clear positions within Douglas's "group and grid" model, other scholars have introduced pragmatic models on how to distinguish certain life modes that shape lifestyle trends today. In his book State, Culture, and Life-Modes: Foundations of Life Mode Analysis (2003), Thomas Hojrup introduced three pragmatic life modes: self-employed life mode, wage earner life mode, and career oriented life mode (Hojrup, 2003). The preceding classification shows that house needs and preferences usually vary based on the income level, work sector, and work style of an individual (Salama, 2011; Graham \& Sabater, 2015). While life modes can be distinguished according to the varying ways in which people work, other factors such as the demographic increase and decrease of families and the associated life modes have been researched by scholars to investigate the dynamics of housing markets.

Coupled with how people work and their family status, the role of leisure- and consumption-oriented life modes can be identified as the third determining factor for housing choice. While some social groups are significantly restricted in their spending, others consciously choose to save their earnings or at least a portion of them. Other groups alternatively opt for a predominantly if not solely consumer-driven lifestyle, as analysed and described by Thorsten Veblen in the late $19^{\text {th }}$ century (Veblen, 2009; Walters, 2006). Nevertheless, among the three types of social groups, work and family status as well as consumption patterns determine housing preferences within the constraints of supply and demand and as part of urban development processes. 


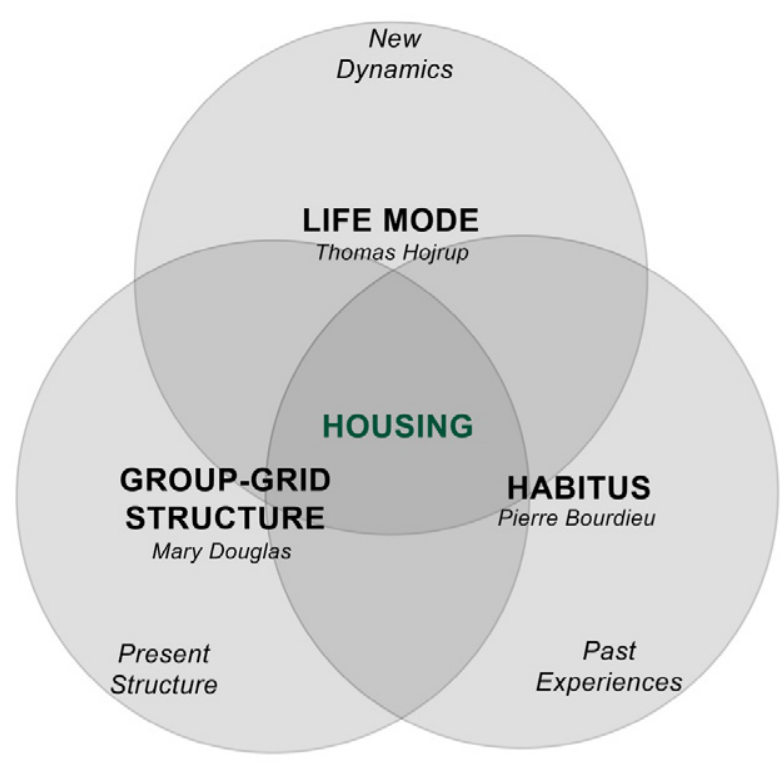

Figure 2. The triadic perspective of lifestyles theories for understanding housing developments, typologies, and choices

By and large, the preceding theories as they relate to housing preferences and choices, establish an agenda, which postulates that lifestyles are important drivers for housing developments, while the existing housing conditions have a reciprocal impact on lifestyles. Lifestyles are a product of individual and collective processes within societies and, therefore, their characteristics are highly complex. Thus, the agenda can be developed to integrate the various parameters that shape the lifestyles of different social groups (Figure 2). According to Bourdieu's theory, society is the product of a historic process and the organisation of a society is directly linked to past experiences. This is manifested in the individual's habitus, which is rooted in cultural customs as well as basic survival needs and the social status. This abstract conception of the foundation of lifestyles in addition to the understanding of the present group-grid structure of a society provides an overview of basic social groups and their roles. The abstract conception of how societies are structured needs to be incorporated into an understanding of predominant life modes as drivers of new restructuring processes. These life modes can be defined by being family-related, or work-based, or leisure-oriented.

\section{Operationalization: From agendas to research programmes}

The two integrationist agendas were developed as frameworks towards implementation in two key research projects funded by Qatar National Research Funds. The Lefebvrian triadic conception of space was advanced from an agenda to a framework and a complete three-year research program, addressing the context of the city of Doha, Qatar, and was implemented during the period between 2011 and 2014. Likewise, the triadic perspective of lifestyles theories for understanding housing developments, typologies, and choices was progressed into comprehensive three-year research program, addressing the larger context of the Gulf region, but with a focus on four major cities: Doha, Manama, Abu-Dhabi and Dubai, and was implemented during the period between 2015 and 2018.

\subsection{Utilising the Lefebvrian triadic conception of space in examining urbanism in the emerging city of Doha}

This project aims to deliver in-depth insights into the various mechanisms of urbanism in an emerging city, whose development is mainly driven by public investments in establishing new knowledge economies to gain independence from reliance on oil resources. Due to the very particular roots of Doha as one of the most recently emerging cities in the Gulf region, four key objectives can be pursued. They are envisaged as a series of questions to provide a multi-dimensional view on the interdependencies between economic, urban, and spatial transformation processes (Salama, Wiedmann, Thierstein, \& Al Ghatam, 2016) (Figure 3):

1) How urban governance evolved historically and how it is structured today:

Urban governance has a direct impact on urban transformation processes by introducing new public investment strategies as well as a new development vision and subsequent physical planning. The project aims to analyse the various forms of how urban governance is rooted in Qatar and how it is transforming to accommodate the new challenge to establish a diversified economy including the introduction of new master planning processes.

2) How companies establish networks within their local surroundings, the region, and worldwide:

The new knowledge economies have led to a complex network of multi-branch companies, which have established their offices in Doha. In order to understand the local, regional and global connectivity of the new economic sectors, the various networks should to be analysed. Based on these network analyses the various degrees of connectivity can be explored, which are a main indicator for the current state of economic transformation in Qatar and its capital city.

3) How the emerging "creative class" uses and perceives and experiences their urban surroundings:

Due to the investment into establishing new economic sectors in addition to the subsequent construction boom a large number of highly educated migrants have moved to Doha. This new socioeconomic class, often referred to as "creative class" (Florida, 2002), is decisive to redefine urbanism in an emerging city. The project thus aims to examine how this new social group is living in Doha and how individuals perceive and experience their 
new surroundings depending on their cultural and socio-economic backgrounds. Additionally, the project aims to understand how these expanding migrant groups use public spaces.

4) How spatial structures have been transformed to accommodate the needs of companies and inhabitants as well as the high urban growth rate itself:

In addition to the various factors defining urban development, the project aims to deliver insights into the spatial dimension of urban growth as well as the very particular redefinition of new urban centres and their spatial accessibility in order to adjust to new economies and their spatial practice.

The framework involves comprehensive analyses of urban planning decision making processes as well as in-depth investigation that applies interlocking network models to examine how urban space is currently used by companies and knowledge intensive economic sectors. Taking into account the importance of the role played by the employees working in these companies and their perception of contemporary urban space in the city, the framework employs empirical research approaches that involve survey studies, focused interviews, observation, and behavioural and cognitive mapping. In addition to investigating the various factors driving spatial transformation, the evolutionary aspects of the city's urban structure are traced and analysed using GIS data and space syntax studies (Salama \& Wiedmann, 2013; Wiedmann, Salama, \& Mirincheva, 2014, 2019). The framework is based on three main hypotheses:

- Urban space is a product of conscious decision making within the public sector (conceived space).

- Urban space is a product of the collective spatial practice of all users (perceived space).

- Urban space is a product of accumulated subjective attachment and identification (lived space).

Based on these three main factors producing urban spaces and thus urban qualities, the research team developed a unique set of four research modules to explore the emerging and newly urbanised areas of Doha that included:

- The analysis of past and present urban governance (urban efficiency).

- The investigation of how the urban environment is used by companies, inhabitants and developers (urban diversity).

- The exploration of how inhabitants perceive the existing urban environment (urban identity).

- The examination of the resulting spatial configuration and current development tendencies (urban space resulting from the three constituents).

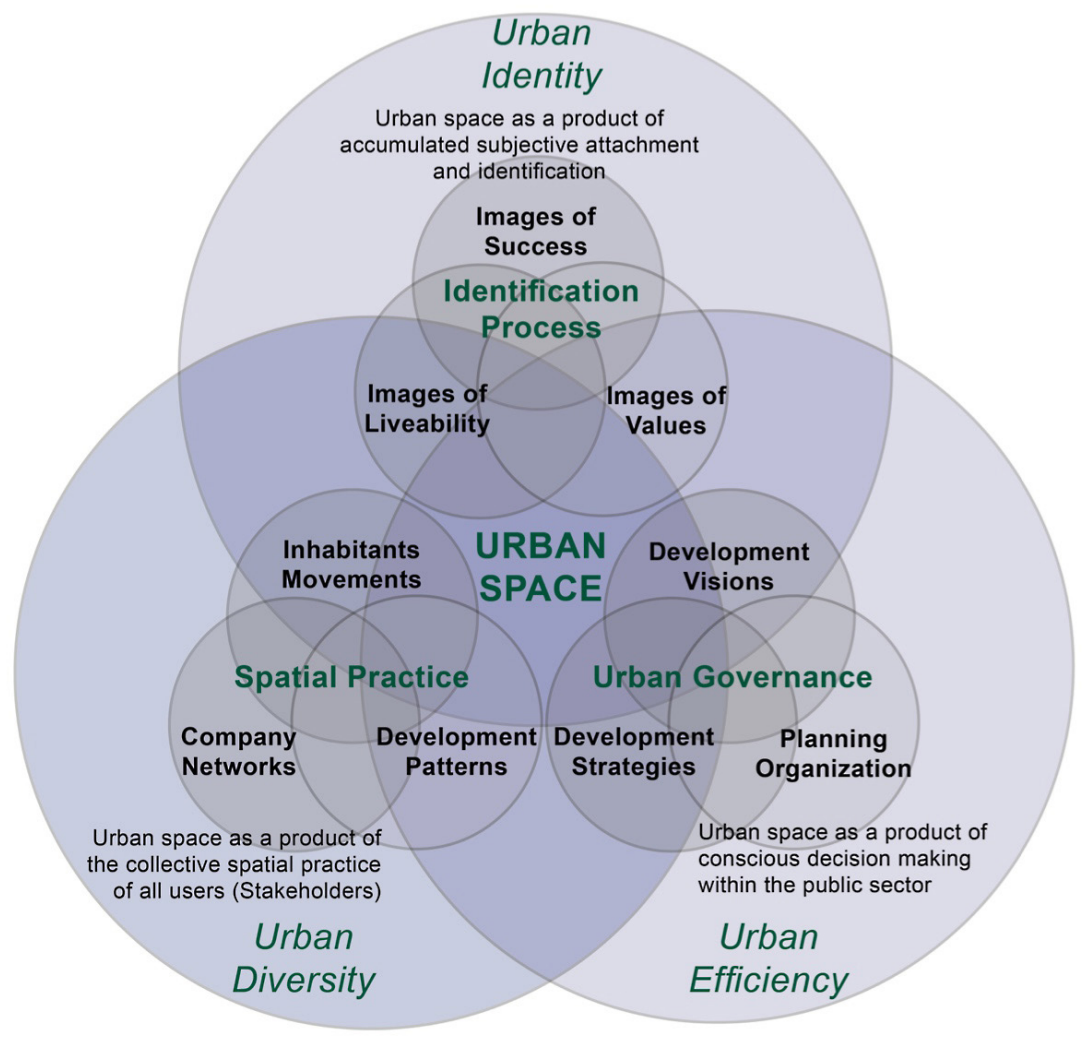

Figure 3. Framework utilising the Lefebvrian triadic conception of space in examining urbanism in the emerging city of Doha (Salama \& Wiedmann, 2013) 


\subsection{Employing the triadic perspective of lifestyles theories for understanding housing developments, typologies, and choices}

Contemporary literature and methodological discourse on housing and typological transformations took place through six approaches: aesthetic or formal interpretations, the typological approach; evolutionary theories and physical explanations such as building technology and climatic aspects; social explanations such as defence theory and household structure; socio-cultural factors; and religious practices. In the Arab world including Gulf States, debates around housing of all types seem to have drifted into two domains that seldom meet:

- Technical discussions about the problems of mass housing including land acquisition, services, credit, finance, and planning for housing.

- Stylistic discussions of the cultural authenticity of housing production.

Nevertheless, issues are always addressed in isolation and many factors critical to the success of housing projects and essential for developing knowledge about existing projects are oversimplified or superficially addressed. Therefore, this research project was launched in 2015 to introduce a new innovative and alternative approach which is critically needed; an approach that has the capacity to address multiple issues at a time while reflecting the thinking spirit of the present era that is based on trans-disciplinarity; the integration of different types of knowledge. Concomitantly, research questions and objectives were developed in a manner that manifests this understanding. The three key research questions stem from the existing knowledge gap resulting from a lack of research that integrates the evolutionary, spatial, and socio-cultural dimensions of housing in the multicultural context of Gulf cities. Consequently, the main questions of this project can be summarised as follows (Salama et al., 2017) (Figure 4):

- How the fast changes in Gulf societies have impacted housing developments and typological transformations?

- What kind of new lifestyles are reflected in the newly emerging housing typologies?

- What approaches are needed to develop housing types amenable to support the quality of life in the Gulf thereby fostering attractiveness and invigorating knowledge economy needs?

In light of the preceding questions, the research objectives are listed below. Each of the objectives involved additional sub-operational objectives enabling the development of an effective research design, methods, and phases:

- Explore the evolution of housing typologies in Gulf cities and their characteristics since the new economic development path has been adopted within the dynamics of socio-cultural transformations.

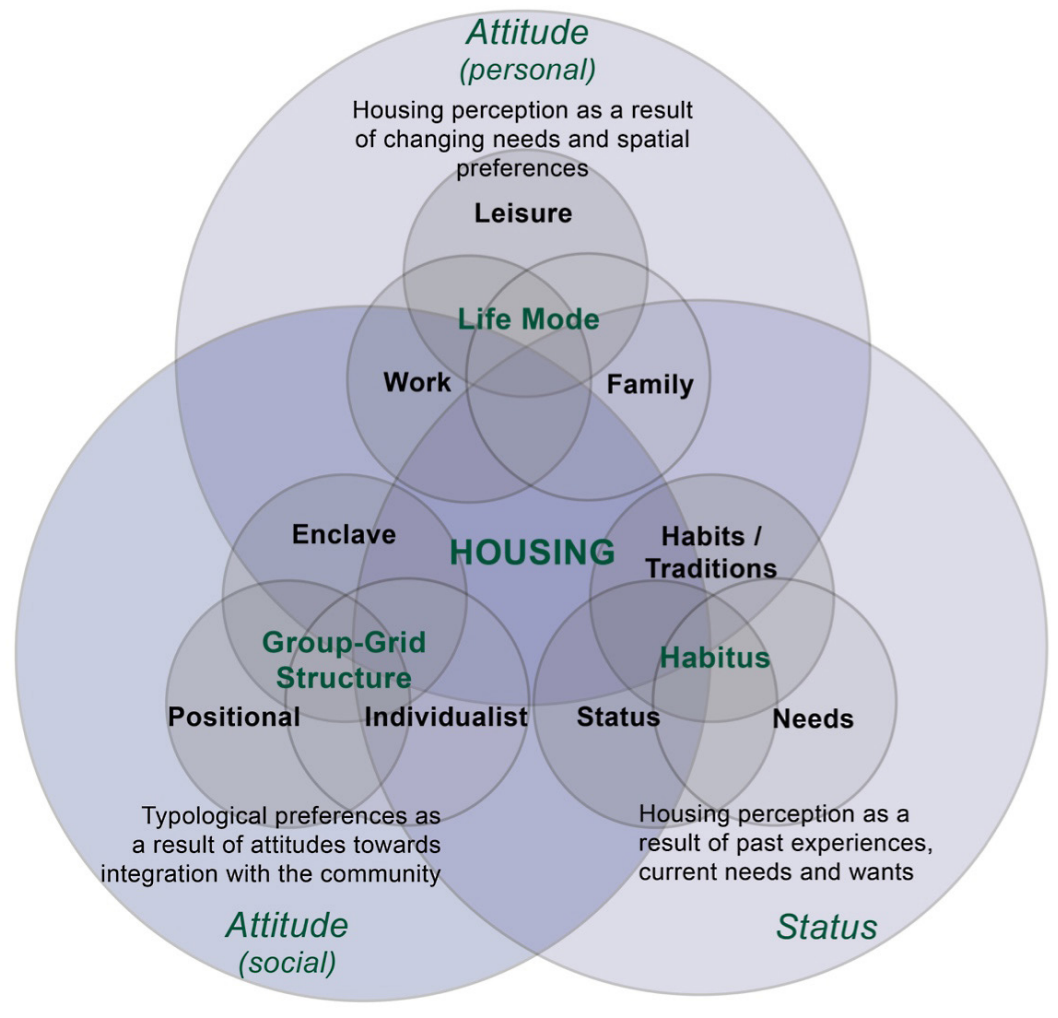

Figure 4. Employing the triadic perspective of lifestyles theories for understanding housing developments, typologies, and choices in four Gulf cities (based on Salama, 2006, 2011; Salama et al., 2017) 
- Investigate contemporary housing and neighbourhood typologies while mapping them to different lifestyles of a multicultural society within the perspective of socio-cultural and socio-economic groups.

- Develop scenario-based design recommendations on how future housing developments can meet the continuously changing structures of multicultural societies in Gulf cities.

It is important to note that the research objectives involved moving from the general to the specific and to the general again so that the utilization of the outcomes was maximized. The first objective addressed the larger context of the Gulf region and involved an overview of four major cities in the Gulf including Doha, Manama, AbuDhabi and Dubai. The second objective dealt with a specific case study on the city of Doha as a rising knowledge economy hub and centre of international migration. The third objective incorporates the outcomes of the first two and develops a validated adaptable scenario with contextbased recommendations amenable to implementation in various contexts in the Gulf.

Based on the notion of trans-disciplinarity and the need for developing new knowledge about housing transformations and typologies, it is noted that achieving the preceding three objectives involved conducting an integrated examination of urban structures and housing typologies. This led to an overview of current housing development tendencies relevant to favoured housing locations, designs and layouts as well as housing unit sizes and other functional and spatial parameters. Coupled with environmental observation studies and attitude surveys the morphological and typological investigations were referred to the sociocultural transformations and the emergence of new lifestyles.

This project was designed in a manner that directly relates to the achievement of its objectives and was based on three main research modules preceded by a preparatory phase and followed by a synthesis phase. Following the same pattern of project objectives, the research modules moved from the generic macro scale to the specific micro scale and then again to the macro scale.

- First, to induct generalities between contextual aspects of housing typological transformations in selected gulf cities, an extensive literature review was conducted. This literature survey focused on contemporary housing development tendencies worldwide and the scientific theories regarding lifestyles.

- This preparatory phase was followed by the first research module focusing on surveying and classifying spatial typologies of housing, which were built during the last decade in key Gulf cities since the construction boom began. Thus, major urban development dynamics were studied in four Gulf cities (Dubai, Doha, Abu Dhabi and Manama).

- The second research module was designed to deduct particularities concerning the specific context of the city of Doha where empirical studies were conducted. This comprehensive case study is thus based on three major phases: a) analyses of dynamics within the local housing market and urban development, b) field studies of selected key exemplary neighbourhoods as well as c) the evaluation of residents' perceptions on housing qualities.

- The third and final research module focused on introducing housing guidelines, which can be utilized to investigate all the key factors that have defined housing during the last ten years and those which will gain importance in future.

\section{Conclusions: Trans-Disciplinary integrationist thinking for city research}

This paper has provided two integrationist agendas for city research by focusing on the essential characteristics of building each agenda while demonstrating the way in which it can be transformed into conceptual frameworks and research programmes. Validating these programmes, the two research projects were utilised. Key lessons can be drawn on how integration through trans-disciplinary thinking can be inducted.

Trans-disciplinarity can be explained as a new form of learning through action involving co-operation among different parts of society, professionals, and academia in order to meet complex challenges of society. Trans-disciplinary research starts from tangible, real-world problems. Solutions are devised in collaboration with multiple stakeholders, including academics and professionals from different disciplinary backgrounds (Pohl \& Hirsch Hadorn, 2008). Thus, Trans-disciplinarity is about blurring then transcending the boundaries of the various disciplines. As a mode of knowledge production it can concurrently encounter complexity while challenging fragmentation of knowledge. Its hybrid nature and non-linearity easily enables it to transcend and indeed incorporate any academic disciplinary structure (Dunnin-Woyseth \& Nielsen, 2004; Lawrence \& Depres, 2004; Doucet \& Janssens, 2011).

The trans-disciplinary framework resulting from the first agenda enables a city research structure that generated outcomes of high significance, on the one hand, for the public sector and its urban planning authorities in the Gulf region. The appraised data facilitate clear insights into how certain economic developments determine and reconfigure urban structures as well as how the existing urban environment is playing an important role in attracting or inhibiting the growth of knowledge economies. Thus, the advantage of a trans-disciplinary city research project based on a holistic framework can come into play allowing planners to gain various insights and explore their own role in reconfiguring urban development pathways. On the other hand, the private sector, including developers, architects and urban planners can benefit where due to the rapid urban growth in recent years most experts engaged within the urban development process have recently moved to Doha seeking engagement in large-scale projects. The short-term stay of many consultants has led to a lack of awareness of development backgrounds and urban dynamics. 
Similarly, the trans-disciplinary framework for examining housing development, provision, choices, and preferences demonstrates that emerging multicultural societies are rooted in extensive international migration and are particularly important cases whereby new housing dynamics and lifestyle trends can be observed. Addressing the fastest growing Gulf cities including Dubai, Abu Dhabi, Doha and Manama as its case studies. This facilitates a cohesive understanding of social structures through characterisation of particular group lifestyles while evaluating data that pertain to housing typologies. The outcome of the implementation process reveals that all four Gulf cities share key characteristics regarding migration patterns, economic restructuring processes and spatial development. Subsequently, key trends in the dynamics between housing typologies and emerging lifestyle groups can be observed in the four cities.

Trans-disciplinary thinking is evident in the first agenda that captures three types of spaces that enables an integrationist approach to city research "conceivedperceived-lived," each of which requires specific disciplinary expertise. These types of expertise are integrated into trans-disciplinary framework and a research programme, validated in the context of the emerging city of Doha, that involves various disciplines architecture, urban design and planning, environmental psychology, economic geography, global studies. Likewise, trans-disciplinary thinking is the crux of the second agenda that establishes parameters for trans-disciplinary knowledge on housing and typological transformations. This is reflected through the utilisation of three lifestyle theories stemming from three different disciplines: sociology, anthropology and ethnography, envisaged and validated to capture an understanding of the housing phenomenon within four gulf cities.

\section{Acknowledgements}

The material presented in this paper stem, in part, from a series of research publications generated from two key grants listed under funding. Thanks are due to colleagues, research associates, and research assistants who have contributed to earlier publications.

\section{Funding}

This work was supported by the Qatar National Research Fund of Qatar Foundation under two grants \# [NPRP 09-1083-6-023] 2011-2014 and \# [NPRP 07-960-5-135] / 2015-2018. The views and findings presented herein are solely the responsibility of the author.

\section{Disclosure statement}

No potential conflict of interest was reported by the authors.

\section{References}

Aerni, P. (2016). Coping with migration-induced urban growth: Addressing the blind spot of UN Habitat. Sustainability, 8(8), 800. https://doi.org/10.3390/su8080800

Appadurai, A. (1996). Modernity at large. University of Minnesota Press, Minneapolis.

Appadurai, A. (Ed.). (2001). Globalization. Duke University Press, Durham. https://doi.org/10.1215/9780822383215

Bardhan, A., \& Kroll, C. A. (2007, 25-27 April). Globalization and the real estate industry: Issues, implications, and opportunities, in The Sloan Industry Studies Annual Conference. Cambridge.

Benedikter, R. (2012). Lifestyles. In H. Anheier \& M. Juergensmeyer (Eds.), Encyclopaedia of global studies (pp. 1076-1080). Sage Publications, London.

https://doi.org/10.4135/9781452218557.n335

Bourdieu, P. (1987). Distinction: A social critique of the judgment of taste. Harvard University Press, Cambridge.

Brenner, N., \& Keil, R. (Eds.). (2006). The global cities reader. Routledge, London.

Bulmer, M. (1984). The Chicago school of sociology: Institutionalization, diversity and the rise of sociological research. University of Chicago Press, Chicago.

Castells, M. (1972). La Question Urbaine. Maspero, Paris.

Castells, M. (1989). The informational city: Information technology, economic restructuring and the urban regional process. Basil Blackwell, Oxford.

Cohen, R. (1981). The new international division of labour, multinational corporations and urban hierarchy. In M. Dear \& A. Scott (Eds.), Urbanization and urban planning in capitalist society (pp. 287-317). Methuen, London. https://doi.org/10.4324/9781351068000-12

Doucet, I., \& Janssens, N. (2011). Transdisciplinarity, hybridization of knowledge production and space related research. In I. Doucet \& N. Janssens (Eds.), Transdisciplinary knowledge production in architecture and urbanism (pp. 1-14). Springer, Heidelberg. https://doi.org/10.1007/978-94-007-0104-5_1

Douglas, M. (1970). Natural symbols: Explorations in cosmology. Cresset Press, London.

Douglas, M. (2006). A history of grid and group cultural theory. In Semioticon 2006. Retrieved from http://semioticon.com/sio/ files/douglas-et-al/douglas1.pdf?lbisphpreq=1\&file=douglaset-al/douglas1.pdf

Dunnin-Woyseth, H., \& Nielsen, M. (2004). Discussing transdisciplinarity: Making professions and the new mode of knowledge production. The Nordic Reader, Oslo School of Architecture, Oslo.

Florida, R. (2002). The rise of the creative class: and how it's transforming work, leisure, community and everyday life. Perseus Book Group, New York.

Freeman, L. (1998). Interpreting the dynamics of public housing: Cultural and rational choice explanations. Housing Policy Debate, 9(2), 323-353. https://doi.org/10.1080/10511482.1998.9521297

Friedman, J., \& Wolff, G. (1982). World city formation: An agenda for research and action. International Journal of Urban and Regional Research, 6(1), 309-344. https://doi.org/10.1111/j.1468-2427.1982.tb00384.x

Graham, E., \& Sabater, A. (2015). Population change and housing across the life course: Demographic perspectives, methodological Challenges and emerging Issues. Working Paper Series (64), ESRC Centre for Population Change. 
Gurran, N., Milligan, V., Baker, D., \& Bugg, L. B. (2007). International practice in planning for affordable housing: Lessons for Australia. Australian Housing and Urban Research Institute, Melbourne.

Hall, P. (2002). Cities of tomorrow. Blackwell Publishing, Oxford.

Harvey, D. (1969). Explanation in geography. Edward Arnold, London.

Harvey, D. (1973). Social justice and the city. Edward Arnold, London.

Hojrup, T. (2003). State, culture, and life modes: The foundations of life mode analysis. Ashgate, Farnham.

Hutchison, R. (2010). Chicago school of urban sociology. In R. Hutchison (Ed.), Encyclopaedia of urban studies (pp. 127130). SAGE Publications, Thousand Oaks. https://doi.org/10.4135/9781412971973.n46

Lawrence, R., \& Depres, C. (2004). Futures of transdisciplinarity. Futures, 36(4), 397-405. https://doi.org/10.1016/j.futures.2003.10.005

Lefebvre, H. (1991). The production of space. Blackwell, Oxford.

Lefebvre, H. (2003). The urban revolution. University of Minnesota, Minneapolis.

Marcus, C. C. (1997). House as a mirror of self. Conari Press, Berkeley.

Merrifield, A. (2006). Henri Lefebvre: A critical introduction. Routledge, London.

Molotch, H. (1976). The city as a growth machine: Towards a political economy of place. American Journal of Sociology, 82, 309-332. https://doi.org/10.1086/226311

Narwold, A., \& Sandy, J. (2010). Valuing housing stock diversity. International Journal of Housing Markets and Analysis, 3(1), 53-59. https://doi.org/10.1108/17538271011027078

Newmark, N. L., \& Thompson, P. J. (1977). Self, space and shelter. Canfield Press, San Francisco.

Walters, G. (2006). Lifestyle theory: Past, present and future. Nova Science Publishers, New York.

Pohl, C., \& Hirsch Hadorn, G. (2008). Core terms in transdisciplinary research. In G. Hirsch Hadorn et al. (Eds.), Handbook of transdsiciplinary research (pp. 427-432). Springer, Heidelberg. https://doi.org/10.1007/978-1-4020-6699-3_28

Salama, A. M. (2006). A lifestyle theories approach for affordable housing research in Saudi Arabia. Emirates Journal for Engineering Research, 11(1), 67-76.
Salama, A. M. (2011). Trans-disciplinary knowledge for affordable housing. Open House International, 36(3), 7-15.

Salama, A. M. (2015). A socio-anthropological approach for exploring housing culture in contemporary Cairo. In A. Picone (Ed.), Culture Mediterranee Dell'abitare: Mediterranean housing cultures. Inhabiting the Future Book Series. Collana, Napoli, 128-137.

Salama, A. M., \& Wiedmann, F. (2013). Demystifying Doha: on architecture and urbanism of an emerging city. Routledge, London.

Salama, A. M., Wiedmann, F., \& Ibrahim, H. G. (2017). Lifestyle trends and housing typologies in emerging multicultural cities. Journal of Architecture and Urbanism, 41(4), 316-327. https://doi.org/10.3846/20297955.2017.1415773

Salama, A. M., Wiedmann, F., Thierstein, A., \& Al Ghatam, W. (2016). Knowledge economy as an initiator of sustainable urbanism in emerging metropolises: The case of Doha, Qatar. ArchNet-IJAR: International Journal of Architectural Research, 10(1), 274-324. https://doi.org/10.26687/archnet-ijar.v10i1.927

Sassen, S. (1991). The Global city: New York, London, Tokyo. Princeton University Press, Princeton.

Shields, R. (1999). Lefebvre, love and struggle: Spatial dialectics. Routledge, London.

Taylor, P. J. (2003). World city network: A global urban analysis. Routledge, London. https://doi.org/10.4324/9780203634059

Turner, J. (1988). The mixed legacy of the Chicago school of sociology. Sociological Perspectives, 31(3), 325-338. https://doi.org/10.2307/1389202

Veblen, T. (2009). The theory of the leisure class. Oxford World's Classics. Oxford: Oxford University Press.

Wiedmann, F., Salama, A. M., \& Mirincheva, V. (2014). Sustainable urban qualities in the emerging city of Doha. Journal of Urbanism, 7(1), 62-84. https://doi.org/10.1080/17549175.2013.870088

Wiedmann, F., Salama, A. M., Ibrahim, H. G., \& Mirincheva, V. (2019). New housing patters and spatial fragmentation in Gulf cities. Journal of Urbanism, ahead of print. https://doi.org/10.1080/17549175.2019.1626263 